\title{
Sphingomonas jaspsi sp. nov., a novel carotenoid-producing bacterium isolated from Misasa, Tottori, Japan
}

\author{
Dalal Asker, Teruhiko Beppu and Kenji Ueda \\ Life Science Research Center, College of Bioresource Sciences, Nihon University, \\ 1866 Kameino, Fujisawa 252-8510, Japan
}

Correspondence

Dalal Asker

dasker@brs.nihon-u.ac.jp
A yellow-pigmented, Gram-negative, motile, strictly aerobic, pleomorphic bacterium (strain TDMA-16 ${ }^{T}$ ) was isolated from a freshwater sample collected at Misasa (Tottori, Japan). Strain TDMA $-16^{\top}$ was slightly tolerant to gamma-ray irradiation and produced carotenoids, including zeaxanthin, nostoxanthin and an unknown carotenoid, effectively [1.7 $\mathrm{mg}$ (g dry cells $\left.)^{-1}\right]$. The DNA $\mathrm{G}+\mathrm{C}$ content of strain TDMA $-16^{\top}$ was $63.3 \mathrm{~mol} \%$. Phylogenetic analysis based on 16S rRNA gene sequences placed strain TDMA $-16^{\top}$ in a distinct lineage in the family Sphingomonadaceae; sequence data showed that strain TDMA $-16^{\top}$ was most closely related to Sphingomonas mali IFO $15500^{\top}$ (95.1\%), Sphingomonas aquatilis JSS7 ${ }^{\top}$ (95.0\%), Sphingomonas pruni IFO $15498^{\top}$ (94.9\%), Sphingomonas melonis DSM $14444^{\top}$ (94.9\%) and Sphingomonas asaccharolytica IFO $15499^{\top}(94.5 \%)$. The major fatty acids of strain TDMA-16 ${ }^{\top}$ were $\mathrm{C}_{17:{ }_{1} \omega 6 c}(34.5 \%)$ and $\mathrm{C}_{18: 1} \omega 7 c(29.3 \%)$. The presence of $\mathrm{Q}-10$ as the main ubiquinone, the Sphingomonadaceaespecific sphingoglycolipid in the polar lipid profile and 2-hydroxy fatty acids, plus the absence of 3-hydroxy fatty acids, supported identification of this strain as a member of the genus Sphingomonas sensu stricto. Phylogenetic distinctiveness and unique phenotypic characteristics differentiated strain TDMA $-16^{\top}$ from closely related Sphingomonas species. The results of polyphasic taxonomic analyses suggest that strain TDMA-16 ${ }^{\top}$ represents a novel Sphingomonas species, for which the name Sphingomonas jaspsi sp. nov. is proposed. The type strain is strain TDMA $-16^{\top}\left(=\right.$ NBRC $102120^{\top}=$ DSM $18422^{\top}=$ CCUG $\left.53607^{\top}\right)$.
The family Sphingomonadaceae belongs to the class Alphaproteobacteria and was first proposed by Kosako et al. (2000). Subsequently, the genus description was emended (Takeuchi et al., 2001; Yabuuchi et al., 2002) and included in the second edition of Bergey's Manual of Systematic Bacteriology (Yabuuchi \& Kosako, 2005). The family comprises the genera Blastomonas, Erythromonas, Sandaracinobacter, Sandarakinorhabdus, Sphingomonas, Sphingosinicella and Zymomonas; it has been proposed recently that the genus Sphingomonas, the type genus of this family that was originally described by Yabuuchi et al. (1990), should be divided into four genera, Sphingomonas sensu stricto and three new genera, Sphingobium, Novosphingobium and Sphingopyxis (Takeuchi et al., 2001). Sphingomonads are strictly aerobic, chemoheterotrophic, Gram-negative bacteria that are of biotechnological interest due to their ability to degrade various xenobiotic substances (Ederer et al., 1997; Zablotowicz et al., 1999; Zipper et al., 1996) and also

The GenBank/EMBL/DDBJ accession number for the 16S rRNA gene sequence of strain TDMA-16 ${ }^{\top}$ is $A B 264131$.

SEMs of cells of strain TDMA- $16^{\top}$ are available as supplementary material with the online version of this paper. their potential to produce useful exopolysaccharides (White et al., 1996) and carotenoids (Silva et al., 2004).

Zeaxanthin $\left(3,3^{\prime}\right.$-dihydroxy- $\beta$-carotene $)$ is a natural, fatsoluble, yellowish carotenoid that is found in some plants, algae and photosynthetic bacteria (Nelis \& De Leenheer, 1989), where it serves as an accessory light-gathering pigment, as well as a protectant against the toxic effects of UV radiation and oxygen radicals. Zeaxanthin is currently utilized as an ingredient in feed for fish and poultry to enhance the pigmentation of animal flesh and egg yolk. Additionally, this pigment has a remarkable potential for use in pharmaceuticals as it prevents age-related macular degeneration and tumour formation. At present, the commercial production of zeaxanthin is carried out mostly by extraction from plant tissues or chemical synthesis. However, there is great potential for the development of a large-scale production system for microbial zeaxanthin.

Recently, some carotenoid-producing bacteria were isolated from freshwater samples that were collected at Misasa (Tottori, Japan), a region known for its high natural radioactivity (Kametani \& Matsumura, 1983). A comprehensive taxonomic characterization based on 16S rRNA gene 
sequences has revealed a unique diversity of carotenoid producers that exist in this radioactive region (D. Asker, T. Beppu \& K. Ueda, unpublished results). Among the isolates, a unique heterotrophic, aerobic, yellow-pigmented bacterium (strain TDMA-16 ${ }^{\mathrm{T}}$ ) was found that belongs to the Sphingomonadaceae. This paper deals with the taxonomic characteristics of this organism.

Strain TDMA- $16^{\mathrm{T}}$ was isolated from a water sample collected at Misasa on 1 September, 2005 by the conventional dilution-plating method using nutrient agar (NA; Difco). Unless otherwise specified, all the characteristics described hereafter are those of cells of strain TDMA- $16^{\mathrm{T}}$ grown on NA for $48 \mathrm{~h}$ at $37^{\circ} \mathrm{C}$. The phylogenetic position of the isolate was studied by using standard analysis based on the $16 \mathrm{~S}$ rRNA gene sequence. The genomic DNA of strain TDMA- $16^{\mathrm{T}}$ was extracted using a bacterial genomic DNA purification kit (Edge BioSystems). The DNA fragment that contained the nearly complete $16 \mathrm{~S}$ rRNA gene of strain TDMA- $16^{\mathrm{T}}$ (1431 bp) was amplified using the bacterial universal primers B8F ( 5 ' -AGAGTTTGATCCTGGCTCAG; nt 8-27 based on Escherichia coli numbering) and B1492R (5'-GGTTACCTTGTTACGACTT; nt 1510-1492 based on E. coli numbering). The $16 \mathrm{~S}$ rRNA gene was sequenced directly by using a BigDye Terminator v3.1 cycle sequencing kit on an ABI 3100 automated DNA sequencer (Applied Biosystems).
A sequence similarity search in the GenBank/EMBL/ DDBJ nucleotide sequence database performed using the program BLASTN (http://www.ncbi.nlm.nih.gov/blast/) revealed that strain TDMA- $16^{\mathrm{T}}$ belongs to the family Sphingomonadaceae. Highest similarity was found with sequences of established species of the genus Sphingomonas sensu stricto including Sphingomonas mali IFO $15500^{\mathrm{T}}$ (95.1\%), Sphingomonas aquatilis $\mathrm{JSS}^{\mathrm{T}}$ (95.0\%), Sphingomonas pruni IFO $15498^{\mathrm{T}}$ (94.9\%), Sphingomonas melonis DSM $14444^{\mathrm{T}}(94.9 \%)$, Sphingomonas asaccharolytica IFO $15499^{\mathrm{T}}$ (94.5\%), Sphingomonas faeni MA-olki ${ }^{\mathrm{T}}$ (94.3\%), Sphingomonas aerolata $\mathrm{NW}^{\mathrm{T}}{ }^{\mathrm{T}}(94.2 \%)$, Sphingomonas abaci $\mathrm{C}^{\mathrm{T}}{ }^{\mathrm{T}}(94.2 \%)$, Sphingomonas echinoides ATCC $14820^{\mathrm{T}}(94.2 \%)$, Sphingomonas panni $\mathrm{C}^{2} 2^{\mathrm{T}}(94.0 \%)$ and Sphingomonas aurantiaca MA101b ${ }^{\mathrm{T}}(93.9 \%)$. These results clearly demonstrated that strain TDMA- $16^{\mathrm{T}}$ represents a novel species within the genus Sphingomonas sensu stricto.

A neighbour-joining phylogenetic tree was constructed using the programs CLUSTAL W (Thompson et al., 1994) and NJ plot (Perrière \& Gouy, 1996). The tree topology was estimated by bootstrap analysis (Felsenstein, 1993) with 1000 resamplings of the dataset. Phylogenetic analysis of a nearly full-length $16 \mathrm{~S}$ rRNA gene sequence of strain TDMA- $16^{\mathrm{T}}$ indicated that it is a member of the genus Sphingomonas sensu stricto (Takeuchi et al., 2001), forming a distinct phylogenetic lineage (Fig. 1). The 16S rRNA gene

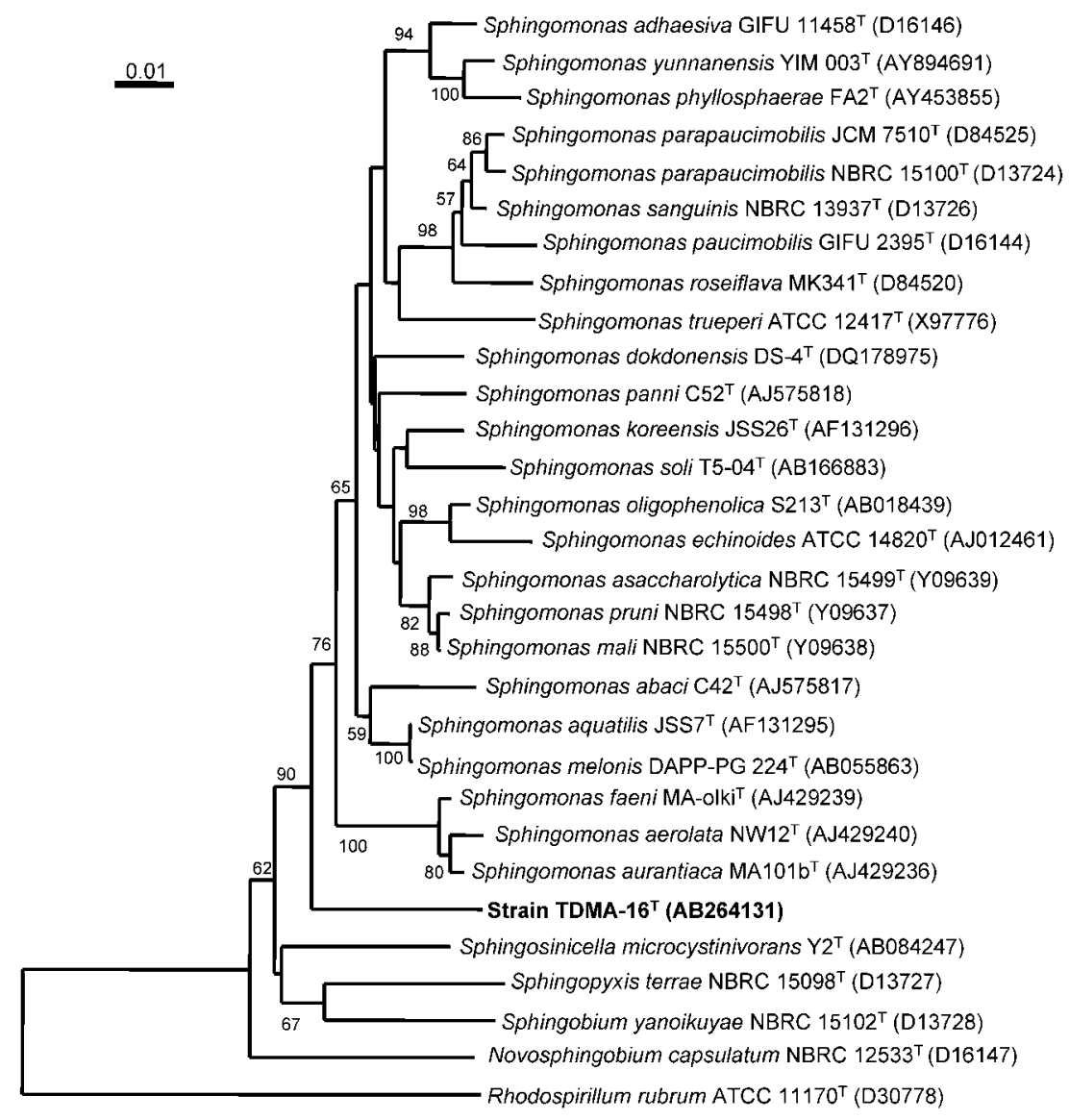

Fig. 1. Phylogenetic tree based on 16S rRNA gene sequences of strain TDMA $-16^{\top}$ and representative members of related species of the genus Sphingomonas sensu stricto. The tree was constructed by using the neighbour-joining method (Saitou \& Nei, 1987). Bar, 1 substitution per $100 \mathrm{nt}$ positions. Bootstrap values, expressed as a percentage of 1000 replicates, are given at the branching points. Values above $50 \%$ are shown. GenBank accession numbers are shown in parentheses. 
sequence of strain TDMA- $16^{\mathrm{T}}$ retained all the signature nucleotides, namely $\mathrm{C}: \mathrm{G}$ at position $52: 359, \mathrm{G}$ at position 134, $\mathrm{G}$ at position 593, $\mathrm{G}: \mathrm{C}$ at position $987: 1218$ and $\mathrm{U}: \mathrm{G}$ at position $990: 1215$ (based on E. coli numbering) (Brosius et al., 1978), that are conserved in the genus Sphingomonas sensu stricto (Takeuchi et al., 2001).

Gram staining was performed according to the method described by Smibert \& Krieg (1994) and bacterial cells were observed under a Zeiss Axioskop 2 microscope (Carl Zeiss Microimaging). SEM observation was performed using a model VE-8800 (Keyence). Anaerobic growth was assessed on NA incubated in a GasPak anaerobic system (BBL). The following tests were performed as described in each reference: casein hydrolysis (Norris et al., 1985); catalase activity, spore formation and hydrolysis of Tween 80, DNA and starch (Smibert \& Krieg, 1994); and hydrolysis of chitin, carboxymethylcellulose (high viscosity; Sigma) and agar (Barrow \& Feltham, 1993). Oxidase activity was tested by using commercial cytochrome oxidase test strips (BioChemika). Other enzyme activities, growth on carbohydrates, acid production from carbohydrates, nitrate reduction, and the production of $\mathrm{H}_{2} \mathrm{~S}$, indole and acetoin were examined using the commercial systems API 20E, API 20NE and API $50 \mathrm{CH}$ (bioMérieux) according to the manufacturer's instructions. To determine optimal growth temperature, the strain was cultivated on NA at 4, 10, 20, 30, 37,40 and $45^{\circ} \mathrm{C}$. $\mathrm{NaCl}$ tolerance was studied using nutrient broth (NB) supplemented with different concentrations of $\mathrm{NaCl}$. Growth at $\mathrm{pH} 3.0-10.0$ was evaluated in NB adjusted with $\mathrm{HCl}$ or $\mathrm{NaOH}$. To determine the survival rate after exposure to gamma radiation, cells of strain TDMA- $16^{\mathrm{T}}$ were grown on NA plates and suspended in NB $(5 \mathrm{ml})$. Aliquots of the cell suspension $(1 \mathrm{ml})$ were irradiated at $2.35 \mathrm{kGy}$ (13 Gy $\mathrm{min}^{-1},{ }^{137} \mathrm{Cs}$ source), serially diluted and plated onto NA. The plates were incubated aerobically at $37^{\circ}$ C. E. coli C600 was treated similarly. Percentage survival was determined by comparison with unirradiated cultures.

Cells of strain TDMA- $16^{\mathrm{T}}$ were Gram-negative, pleomorphic, motile, short rods $(0.4-0.5 \times 0.7-1.0 \mu \mathrm{m})$. Spores were not observed. Buds formed on the mature cells (see SEMs available as Supplementary Fig. S1 in IJSEM Online). Strain TDMA- $16^{\mathrm{T}}$ formed yellow-pigmented, convex, circular colonies (1-2 $\mathrm{mm}$ in diameter) after $48 \mathrm{~h}$ incubation at $37^{\circ} \mathrm{C}$. The temperature range for growth of strain TDMA- $16^{\mathrm{T}}$ was $20-40{ }^{\circ} \mathrm{C}$ (optimum, $35-37^{\circ} \mathrm{C}$ ). No growth occurred at $45^{\circ} \mathrm{C}$. The $\mathrm{pH}$ range for growth was $\mathrm{pH}$ 6.0-9.0 (optimum, pH 6.0-7.0). Strain TDMA- $16^{\mathrm{T}}$ was strictly aerobic and chemo-organotrophic. The strain was positive for oxidase and catalase, but negative in the oxidation/ fermentation test and gas/acid production test with glucose. Strain TDMA- $16^{\mathrm{T}}$ was slightly tolerant to gamma-ray irradiation, showing $0.45 \%$ survival rate after exposure to a $2.3 \mathrm{kGy}$ dose (13 Gy $\min ^{-1},{ }^{137} \mathrm{Cs}$ source). At this dose, the survival rate of E. coli $\mathrm{C} 600$ was $0 \%$.

Other phenotypic properties of strain TDMA- $16^{\mathrm{T}}$ are given in the species description and those characteristics that differentiate strain TDMA- $16^{\mathrm{T}}$ from related members of the genus Sphingomonas sensu stricto are listed in Table 1.

Unlike Sphingomonas mali IFO $15500^{\mathrm{T}}$, Sphingomonas pruni IFO $15498^{\mathrm{T}}$, Sphingomonas asaccharolytica IFO $15499^{\mathrm{T}}$, Sphingomonas melonis DSM $14444^{\mathrm{T}}$ and Sphingomonas dokdonensis DS- $4^{\mathrm{T}}$, strain TDMA- $16^{\mathrm{T}}$ showed severe growth arrest in the presence of $>0.25 \% \mathrm{NaCl}$. Strain TDMA- $16^{\mathrm{T}}$ differed from Sphingomonas mali IFO $15500^{\mathrm{T}}$, Sphingomonas aerolata $\mathrm{NW}_{12}^{\mathrm{T}}$, Sphingomonas faeni $\mathrm{MA}-\mathrm{olki}^{\mathrm{T}}$ and Sphingomonas aurantiaca MA101b ${ }^{\mathrm{T}}$ by: (i) being unable to assimilate L-arabinose, D-mannose, $\mathrm{N}$-acetyl-D-glucosamine, gluconate or adipate; (ii) being able to hydrolyse gelatin and starch; and (iii) being unable to hydrolyse aesculin or DNA. Strain TDMA-16 ${ }^{\mathrm{T}}$ differed from Sphingomonas pruni IFO $15498^{\mathrm{T}}$ and Sphingomonas asaccharolytica IFO $15499^{\mathrm{T}}$ by: (i) being unable to assimilate L-arabinose, D-mannose or $\mathrm{N}$-acetyl-D-glucosamine; (ii) being able to hydrolyse gelatin; and (iii) being unable to hydrolyse aesculin. Strain TDMA- $16^{\mathrm{T}}$ differed from Sphingomonas melonis DSM $14444^{\mathrm{T}}$ by: (i) being motile; (ii) being unable to assimilate L-arabinose, D-mannose, $\mathrm{N}$-acetyl-D-glucosamine or DL-malic acid; (iii) being able to hydrolyse gelatin and starch; and (iv) being unable to hydrolyse aesculin. Strain TDMA- $16^{\mathrm{T}}$ differed from Sphingomonas aquatilis JSS7 $^{\mathrm{T}}$ by: (i) being unable to assimilate L-arabinose; (ii) being able to assimilate glucose; and (iii) being able to hydrolyse gelatin. Additionally, strain TDMA- $16^{\mathrm{T}}$ could be distinguished from other closely related species by the traits detailed in Table 1.

The yellow pigments were extracted by agitating bacterial cells in methanol on a rotary shaker $\left(100\right.$ r.p.m.) at $50{ }^{\circ} \mathrm{C}$ in the dark until the cells were bleached followed by centrifugation at $5000 \mathrm{~g}$ for $5 \mathrm{~min}$. The resultant supernatant was scanned for absorbance between 260 and $700 \mathrm{~nm}$ at room temperature on a Hitachi U2000 spectrophotometer. Carotenoid composition was characterized by HPLC-MS (LCMS-2010EV; Shimadzu) using a Shim-Pack FC-ODS $(150 \times 4.6 \mathrm{~mm}, 5 \mu \mathrm{m}$ particle size; column temperature $35^{\circ} \mathrm{C}$ ) and acetonitrile: methanol:tetrahydrofuran $(5.8: 3.5: 0.7$, by vol. $)$ as the mobile phase at a flow rate of $0.8 \mathrm{ml} \mathrm{min}-1$. Zeaxanthin was identified by its retention time, absorption spectrum and molecular mass. Commercial zeaxanthin (DHI; Water \& Environment) was used as a standard. The menaquinone content was determined by an HPLC method (Collins, 1994) using an extract of Sphingopyxis alaskensis DSM $13593^{\mathrm{T}}$ and Sphingomonas asaccharolytica NBRC $15499^{\mathrm{T}}$ as a reference for Q-10. The fatty acid methyl esters of strain TDMA- $16^{\mathrm{T}}$ were extracted and analysed according to the standard protocol of the Sherlock Microbial Identification System (version 5.0; MIDI). Glycosphingolipids were analysed by TLC as described by Kawahara et al. (1991) and Takeuchi et al. (2001). Polar lipids were determined according to Tindall (1990). The DNA $\mathrm{G}+\mathrm{C}$ content was determined by using an HPLC method (Mesbah \& Whitman, 1989). 
Table 1. Differential characteristics of strain TDMA $-16^{\top}$ (Sphingomonas jaspsi sp. nov.) and related type strains

Strains: 1, strain TDMA-16 ${ }^{\mathrm{T}}$; 2, Sphingomonas mali IFO $15500^{\mathrm{T}}$ (data from Takeuchi et al., 2001); 3, Sphingomonas pruni IFO 15498 ${ }^{\mathrm{T}}$ (Takeuchi et al., 2001); 4, Sphingomonas asaccharolytica IFO $15499^{\mathrm{T}}$ (Takeuchi et al., 2001); 5, Sphingomonas aquatilis JSS7 ${ }^{\mathrm{T}}$ (Lee et al., 2001); 6, Sphingomonas melonis DSM 14444 ${ }^{\mathrm{T}}$ (Buonaurio et al., 2002; Busse et al., 2005); 7, Sphingomonas abaci C42 ${ }^{\mathrm{T}}$ (Busse et al., 2005); 8, Sphingomonas aerolata $\mathrm{NW}^{\mathrm{T}}$ (Busse et al., 2003); 9, Sphingomonas faeni MA-olki ${ }^{\mathrm{T}}$ (Busse et al., 2003); 10, Sphingomonas aurantiaca MA101b $^{\mathrm{T}}$ (Busse et al., 2003); 11, Sphingomonas echinoides ATCC $14820^{\mathrm{T}}$ (Denner et al., 1999); 12, Sphingomonas soli T5-04 ${ }^{\mathrm{T}}$ (Yang et al., 2006); 13, Sphingomonas koreensis JSS26 ${ }^{\mathrm{T}}$ (Lee et al., 2001); 14, Sphingomonas panni $\mathrm{C}^{2} 2^{\mathrm{T}}$ (Busse et al., 2005); 15, Sphingomonas dokdonensis DS-4 ${ }^{\mathrm{T}}$ (Yoon et al., 2006). +, Positive; (+), weakly positive; -, negative; ND, not determined; NG, no growth; V, variable. All strains are negative for urease activity, indole production, glucose fermentation, arginine dihydrolase, and assimilation of D-mannitol, caprate and acetate.

\begin{tabular}{|c|c|c|c|c|c|c|c|c|c|c|c|c|c|c|c|}
\hline Characteristic & 1 & 2 & 3 & 4 & 5 & 6 & 7 & 8 & 9 & 10 & 11 & 12 & 13 & 14 & 15 \\
\hline Colony colour ${ }^{\star}$ & DY & LY & LY & LY & $\mathrm{Y}$ & DY & $\mathrm{O}$ & $\mathrm{O}$ & $\mathrm{O}$ & $\mathrm{O}$ & Y & Y & Y & $\mathrm{Y}$ & $\mathrm{Y}$ \\
\hline Cell shape $\dagger$ & PSR & $\mathrm{R}$ & $\mathrm{R}$ & $\mathrm{R}$ & $\mathrm{R}$ & $\mathrm{R}$ & $\mathrm{R}$ & $\mathrm{R}$ & $\mathrm{R}$ & $\mathrm{R}$ & $\mathrm{R}$ & $\mathrm{R}$ & $\mathrm{R}$ & $\mathrm{R}$ & $\mathrm{R}$ \\
\hline Budding formation & + & - & - & - & - & - & - & - & - & - & - & - & - & - & - \\
\hline Growth in $3 \% \mathrm{NaCl}$ & - & + & + & + & $\mathrm{ND}$ & + & $\mathrm{ND}$ & $\mathrm{ND}$ & $\mathrm{ND}$ & ND & ND & $\mathrm{ND}$ & $\mathrm{ND}$ & $\mathrm{ND}$ & + \\
\hline L-Arabinose & - & $(+)$ & + & $(+)$ & + & + & - & + & + & + & + & + & - & - & - \\
\hline D-Mannose & - & + & + & $(+)$ & - & + & - & + & + & + & - & - & - & $(+)$ & + \\
\hline $\mathrm{N}$-Acetyl-D-glucosamine & - & + & + & + & - & + & - & + & + & + & + & - & + & - & - \\
\hline Maltose & $(+)$ & + & + & + & + & + & - & + & + & + & $(+)$ & + & + & $(+)$ & - \\
\hline Gluconate & - & + & + & - & - & - & $(+)$ & + & + & + & - & - & - & - & - \\
\hline$\beta$-Galactosidase & + & + & + & + & + & + & $\mathrm{ND}$ & + & $(+)$ & $(+)$ & + & - & + & $\mathrm{ND}$ & - \\
\hline Oxidase activity & + & + & + & + & + & + & - & + & + & + & + & + & + & - & + \\
\hline \multicolumn{16}{|l|}{ Hydrolysis of: } \\
\hline Aesculin & - & + & + & + & - & + & + & + & + & + & + & + & - & + & + \\
\hline Gelatin & $(+)$ & - & - & - & - & - & $\mathrm{ND}$ & - & - & - & - & + & - & $\mathrm{ND}$ & + \\
\hline Starch & + & - & + & + & $\mathrm{ND}$ & - & ND & - & - & - & $\mathrm{ND}$ & ND & $\mathrm{ND}$ & $\mathrm{ND}$ & + \\
\hline Tween 80 & + & + & + & + & $\mathrm{ND}$ & - & $\mathrm{ND}$ & $\mathrm{ND}$ & $\mathrm{ND}$ & $\mathrm{ND}$ & ND & ND & $\mathrm{ND}$ & $\mathrm{ND}$ & + \\
\hline DNA & NG & + & NG & NG & $\mathrm{ND}$ & NG & $\mathrm{ND}$ & $(+)$ & $(+)$ & $\mathrm{V}$ & $\mathrm{ND}$ & ND & $\mathrm{ND}$ & $\mathrm{ND}$ & $\mathrm{ND}$ \\
\hline DNA G + C content $(\mathrm{mol} \%)$ & 63.3 & $65.4-65.9$ & 65.4 & 64.8 & 63.0 & 65.0 & ND & 65.4 & 63.1 & 64.7 & 65.8 & 63.9 & 66.0 & $\mathrm{ND}$ & 66.9 \\
\hline
\end{tabular}

${ }^{\star}$ Y, Yellow; LY, light yellow; DY, deep yellow; O, orange.

$\dagger$ PSR, Pleomorphic short rods; R, rods.

The yellow pigments of strain TDMA- $16^{\mathrm{T}}$ were identified as carotenoids, including zeaxanthin [UV-vis $\lambda_{\max } 451$ and $476 \mathrm{~nm}$; molecular mass $\left.\left(\mathrm{M}^{+}+1\right), 569\right]$, nostoxanthin [UVvis $\lambda_{\max } 449$ and $475 \mathrm{~nm}$; molecular mass $\left.\left(\mathrm{M}^{+}+1\right), 601\right]$ and an unidentified polar carotenoid. Nostoxanthin is also found in Sphingomonas paucimobilis and Sphingomonas echinoides (Jenkins et al., 1979; Rowe et al., 2000). The quinone system of strain TDMA- $16^{\mathrm{T}}$ consisted mainly of ubiquinone Q-10. This quinone profile is a characteristic of the majority of species within the class Alphaproteobacteria (Collins \& Jones, 1981), including the genus Sphingomonas sensu stricto (Busse et al., 1999; Takeuchi et al., 2001). The polar lipid profile of strain TDMA- $16^{\mathrm{T}}$ was characterized by the presence of phosphatidylethanolamine, phosphatidylglycerol, diphosphatidylglycerol, sphingoglycolipid and an unidentified glycolipid as the predominant lipids and moderate amounts of two unidentified glycolipids. Additionally, strain TDMA- $16^{\mathrm{T}}$ contained minor amounts of various unidentified lipids, including an aminophospholipid and two glycolipids. Phosphatidylmonomethylethanolamine and phosphatidyldimethylethanolamine were not detected in strain TDMA-16 ${ }^{\mathrm{T}}$. The polar lipid profile of strain TDMA-16 ${ }^{\mathrm{T}}$ was distinguishable from that of Sphingomonas mali, Sphingomonas pruni and Sphingomonas asaccharolytica in that phosphatidylmonomethylethanolamine and phosphatidyldimethylethanolamine were absent (Busse et al., 1999; Kämpfer et al., 1997). The major fatty acids were $\mathrm{C}_{17: 1} \omega 6 c(34.5 \%)$ and $\mathrm{C}_{18: 1} \omega 7 c(29.3 \%)$. Table 2 shows the detailed fatty acid composition of strain TDMA $-16^{\mathrm{T}}$. This profile is in excellent agreement with 
those of representatives of the genus (Table 2) (Busse et al., 1999, 2005, 2003; Yang et al., 2006) and consistent with the assignment of strain TDMA- $16^{\mathrm{T}}$ to the genus Sphingomonas sensu stricto. The presence of 2-hydroxy fatty acids and the lack of 3-hydroxy fatty acids are important characteristics of members of the family Sphingomonadaceae (Busse et al., 1999; Takeuchi \& Hiraishi, 2001; Takeuchi et al., 2001). However, strain TDMA- $16^{\mathrm{T}}$ differed from members of the genus Sphingomonas sensu stricto both qualitatively and quantitatively with regard to certain fatty acids and by the presence of 2-OH $\mathrm{C}_{18: 1}$ as the major hydroxy fatty acid (Table 2).
The DNA G+C content of strain TDMA- $16^{\mathrm{T}}$ was $63.3 \mathrm{~mol} \%$ (Table 1), which is in agreement with the values of $62-68 \mathrm{~mol} \%$ given for the genus (Takeuchi et al., 2001).

The results of the analysis of the 16S rRNA gene sequence, quinone system, fatty acids, polar lipids and DNA G $+\mathrm{C}$ content thus proved that strain TDMA- $16^{\mathrm{T}}$ is a member of the genus Sphingomonas sensu stricto. The strain can be distinguished from its close relatives by its $16 \mathrm{~S}$ rRNA gene sequence, fatty acid composition and numerous physiological characteristics. On the basis of these results, it is

Table 2. Comparison of whole-cell fatty acid profiles of strain TDMA-16 ${ }^{\top}$ (Sphingomonas jaspsi sp. nov.) and related species

Taxa: 1, strain TDMA-16 ${ }^{\mathrm{T}}$; 2, Sphingomonas mali IFO $15500^{\mathrm{T}}$ (data from Yang et al., 2006); 3, Sphingomonas pruni IFO $15498^{\mathrm{T}}$ (Yang et al., 2006); 4, Sphingomonas asaccharolytica IFO $15499^{\mathrm{T}}$ (Yang et al., 2006); 5, Sphingomonas aquatilis $\mathrm{JSS7}^{\mathrm{T}}$ (Busse et al., 2005); 6, Sphingomonas melonis DSM $14444^{\mathrm{T}}$ (Busse et al., 2005); 7, Sphingomonas abaci $\mathrm{C}^{\mathrm{T}}{ }^{\mathrm{T}}$ (Busse et al., 2005); 8, Sphingomonas aerolata (three strains; Busse et al., 2003); 9, Sphingomonas faeni MA-olki ${ }^{\mathrm{T}}$ (Busse et al., 2003); 10, Sphingomonas aurantiaca (three strains; Busse et al., 2003); 11, Sphingomonas echinoides ATCC $14820^{\mathrm{T}}$ (Denner et al., 1999); 12, Sphingomonas soli $\mathrm{T5}-04^{\mathrm{T}}$ (Yang et al., 2006); 13, Sphingomonas koreensis $\mathrm{JSS26}^{\mathrm{T}}$ (Busse et al., 2005); 14, Sphingomonas panni $\mathrm{C}^{\mathrm{T}}{ }^{\mathrm{T}}$ (Busse et al., 2005); 15, Sphingomonas dokdonensis DS-4 ${ }^{\mathrm{T}}$ (Yoon et al., 2006). Values are percentages of total fatty acids.

\begin{tabular}{|c|c|c|c|c|c|c|c|c|c|c|c|c|c|c|c|}
\hline Fatty acid & 1 & 2 & 3 & 4 & 5 & 6 & 7 & 8 & 9 & 10 & 11 & 12 & 13 & 14 & 15 \\
\hline \multicolumn{16}{|l|}{ Saturated } \\
\hline $\mathrm{C}_{14: 0}$ & 0.4 & 1.4 & 16.8 & & 0.7 & 1.0 & & $1.6-1.9$ & 2.0 & $2.1-3.0$ & 0.9 & & 2.6 & 1.1 & 0.8 \\
\hline$C_{15: 0}$ & 2.1 & 0.2 & & 3.8 & & 0.5 & & $0.0-0.5$ & & $0.0-0.8$ & & 0.8 & & 1.1 & \\
\hline$C_{16: 0}$ & 4.2 & 10.9 & 16.9 & 7.5 & 18.4 & 10.9 & 12.4 & $12.0-15.8$ & 11.2 & $12.2-15.6$ & 10.0 & 14.3 & 13.0 & 17.8 & 19.0 \\
\hline$C_{17: 0}$ & 3.8 & & & 8.9 & & & & & & $0.0-0.2$ & & & & & \\
\hline$C_{18: 0}$ & 0.2 & 0.5 & & 0.4 & 1.2 & 0.9 & & & & $0.0-0.3$ & & 0.5 & 0.8 & & \\
\hline $\mathrm{C}_{17: 0}$ cyclo & & & & & 0.4 & & & $0.0-0.4$ & & & & & & & \\
\hline $\mathrm{C}_{19: 0}$ cyclo $\omega 8 \mathrm{c}$ & & & & & 0.4 & 0.5 & & & 0.8 & $0.4-0.7$ & & & & & \\
\hline \multicolumn{16}{|l|}{ Unsaturated } \\
\hline$C_{15: 1} \omega 6 c$ & 0.2 & & & & & & & & & & & & & & \\
\hline $\mathrm{C}_{16: 1} \omega 5 c$ & 2.0 & & & & 1.0 & 1.1 & & $1.2-2.0$ & 1.6 & $1.6-1.8$ & 0.8 & & 1.6 & 2.1 & 1.3 \\
\hline $\mathrm{C}_{16: 1} \omega 7 c$ & & & & & & & & & & & 2.9 & & & & \\
\hline$C_{16: 1}$ & & 1.4 & & & & & & & & & & & & & \\
\hline$C_{17: 1} \omega 6 c$ & 34.5 & & & & 0.4 & 2.6 & 1.6 & $0.0-1.7$ & 2.6 & $0.8-3.0$ & & & 0.8 & 3.6 & \\
\hline $\mathrm{C}_{17: 1}$ & & 1.7 & 4.9 & 27.5 & & & & & & & & 9.6 & & & \\
\hline $\mathrm{C}_{18: 1} \omega 5 c$ & 2.1 & 1.8 & & & 1.5 & 2.0 & & $0.6-0.8$ & 1.0 & $0.6-1.0$ & 2.7 & & 1.4 & 0.7 & \\
\hline $\mathrm{C}_{18: 1} \omega 7 c$ & 29.3 & & & & 60.3 & 63.0 & 64.8 & & & & & & 62.5 & 51.3 & 45.7 \\
\hline 11-Methyl $C_{18: 1} \omega 7 c$ & & & & & 5.4 & 6.9 & & & & $0.0-3.5$ & & & 4.1 & & 6.3 \\
\hline \multicolumn{16}{|l|}{ Hydroxy } \\
\hline $2-\mathrm{OH} \mathrm{C} \mathrm{C}_{12: 0}$ & & & & & & & & $0.3-0.6$ & 0.6 & 0.4 & & & & & \\
\hline $2-\mathrm{OH} \mathrm{C} \mathrm{C}_{13: 0}$ & 0.1 & & & & & & & & & & & & & & \\
\hline $2-\mathrm{OH} \mathrm{C} \mathrm{C}_{14: 0}$ & 0.7 & 9.8 & & 0.4 & 5.5 & 7.6 & 12.9 & $8.7-14.1$ & 9.7 & $10.0-10.6$ & 7.2 & 3.4 & 7.5 & 5.3 & 12.1 \\
\hline $2-\mathrm{OH} \mathrm{C} \mathrm{C}_{15: 0}$ & 0.5 & 0.3 & & 1.0 & & 0.5 & & & & & & 0.9 & & & \\
\hline $2-\mathrm{OH} \mathrm{C} 16: 0$ & 0.4 & 0.8 & & & & 0.8 & & & & & & & & & \\
\hline $2-\mathrm{OH} \mathrm{C} \mathrm{C}_{16: 1}$ & & & & & & & & $0.0-0.5$ & & & & & & & \\
\hline $2-\mathrm{OH} \mathrm{C} \mathrm{C}_{18: 1}$ & 6.1 & & & & 0.6 & & & & & & & & 0.8 & & \\
\hline \multicolumn{16}{|l|}{ Summed features* } \\
\hline 4 & 8.1 & 2.1 & 2.5 & & 4.3 & 1.4 & 8.3 & $24.6-26.8$ & 29.2 & $25.7-28.0$ & 2.45 & 3.9 & 5.0 & 17.1 & 14.8 \\
\hline 7 & 0.5 & 69.2 & 58.4 & 50.2 & & & & $38.5-46.0$ & 41.4 & $40.0-40.5$ & 73.1 & 65.5 & & & \\
\hline
\end{tabular}

${ }^{*}$ Summed feature 4 contains $2-\mathrm{OH}$ iso- $\mathrm{C}_{15: 0}$ and/or $\mathrm{C}_{16: 1} \omega 7 c$. Summed feature 7 contains $\mathrm{C}_{18: 1} \omega 7 c, \mathrm{C}_{18: 1} \omega 9 t$ and/or $\mathrm{C}_{18: 1} \omega 12 t$. 
concluded that strain TDMA- $16^{\mathrm{T}}$ represents a novel carotenoid-producing species of the genus Sphingomonas sensu stricto, for which the name Sphingomonas jaspsi sp. nov. is proposed.

\section{Description of Sphingomonas jaspsi sp. nov.}

Sphingomonas jaspsi [ja.sp'.si. N.L. n. jaspsum arbitrary name derived from the acronym JSPS (Japan Society for the Promotion of Science); N.L. gen. n. jaspsi of JSPS, the organization that supported this study].

Cells are Gram-negative-staining pleomorphic short rods that are strictly aerobic, motile and non-spore-forming. Cells are $0.4-0.5 \mu \mathrm{m}$ in width and $0.7-1.0 \mu \mathrm{m}$ in length. Budding morphology may be observed. On NA, forms yellow, circular, dry colonies (1-2 $\mathrm{mm}$ in diameter) within $48 \mathrm{~h}$. Carotenoids such as zeaxanthin and nostoxanthin are produced. Grows at $20.0-40.0^{\circ} \mathrm{C}$ (optimum, $35.0-37.0^{\circ} \mathrm{C}$ ) and $\mathrm{pH}$ 6.0-9.0 (optimum, $\mathrm{pH}$ 6.0-7.0). Optimal growth occurs in the absence of $\mathrm{NaCl}$; growth is inhibited by the presence of $>0.25 \%(\mathrm{w} / \mathrm{v}) \mathrm{NaCl}$. Anaerobic growth does not occur. Tween 80 , gelatin and starch are hydrolysed, whereas aesculin, agar, DNA, casein, cellulose and chitin are not. Negative reactions are observed for glucose fermentation and acid production from all tested sugars. Indole and $\mathrm{H}_{2} \mathrm{~S}$ are not produced. Nitrate is not reduced. Catalaseand oxidase-positive. $\beta$-Galactosidase-positive. Negative for tryptophan deaminase, lysine decarboxylase, ornithine decarboxylase, tryptophan deaminase and urease activities. Glucose and maltose are assimilated, but arabinose, mannose, mannitol, $\mathrm{N}$-acetylglucosamine, gluconate, capric acid, adipic acid, malate, trisodium citrate and phenylacetic acid are not. The major fatty acids are $\mathrm{C}_{17: 1} \omega 6 c(34.5 \%)$, $\mathrm{C}_{18: 1} \omega 7 c(29.3 \%)$ and summed feature 4 (containing $\mathrm{C}_{16: 1} \omega 7 c$ and/or $2-\mathrm{OH}$ iso- $\left.\mathrm{C}_{15: 0}\right)(8.1 \%)$. The major hydroxy fatty acid is $2-\mathrm{OH} \mathrm{C} \mathrm{C}_{18: 1}(6.1 \%)$. The predominant ubiquinone is Q-10. Glycosphingolipids are present.

The type strain is TDMA $-16^{\mathrm{T}}\left(=\mathrm{NBRC} 102120^{\mathrm{T}}=\mathrm{DSM}\right.$ $18422^{\mathrm{T}}=$ CCUG $53607^{\mathrm{T}}$ ), which was isolated from a freshwater sample collected at Misasa (Tottori, Japan). The DNA $\mathrm{G}+\mathrm{C}$ content of the type strain is $63.3 \mathrm{~mol} \%$.

\section{Acknowledgements}

We would like to thank the editor and the two anonymous referees whose insightful suggestions significantly improved the paper. We thank Akira Seto for the sample collection, Hoshio Eguchi for his assistance with the gamma-ray irradiation and Shoichi Amano for his assistance with the electron microscopic observations. We also thank Dr Tarek S. Awad for critical reading of the manuscript. This research was supported by the 21st century COE program of the Ministry of Education, Culture, Sports, Science and Technology, Japan. D. A. was supported by a fellowship from the Japan Society for the Promotion of Science.

\section{References}

Barrow, G. I. \& Feltham, R. K. A. (1993). Cowan and Steel's Manual for the Identification of Medical Bacteria, 3rd edn. Cambridge: Cambridge University Press.
Brosius, J., Palmer, M. L., Kennedy, P. J. \& Noller, H. F. (1978). Complete nucleotide sequence of a $16 \mathrm{~S}$ ribosomal RNA gene from Escherichia coli. Proc Natl Acad Sci U S A 75, 4801-4805.

Buonaurio, R., Stravato, V. M., Kosako, Y., Fujiwara, N., Naka, T., Kobayashi, K., Cappelli, C. \& Yabuuchi, E. (2002). Sphingomonas melonis sp. nov., a novel pathogen that causes brown spots on yellow Spanish melon fruits. Int J Syst Evol Microbiol 52, 2081-2087.

Busse, H. J., Kämpfer, P. \& Denner, E. B. (1999). Chemotaxonomic characterisation of Sphingomonas. J Ind Microbiol Biotechnol 23, 242-251.

Busse, H. J., Denner, E. B. M., Buczolits, S., Salkinoja-Salonen, M., Bennasar, A. \& Kämpfer, P. (2003). Sphingomonas aurantiaca sp. nov., Sphingomonas aerolata sp. nov. and Sphingomonas faeni sp. nov., air- and dustborne and Antarctic, orange-pigmented, psychrotolerant bacteria, and emended description of the genus Sphingomonas. Int J Syst Evol Microbiol 53, 1253-1260.

Busse, H. J., Hauser, E. \& Kämpfer, P. (2005). Description of two novel species, Sphingomonas abaci sp. nov. and Sphingomonas panni sp. nov. Int J Syst Evol Microbiol 55, 2565-2569.

Collins, M. D. (1994). Isoprenoid quinones. In Chemical Methods in Prokaryotic Systematics, pp. 265-310. Edited by M. Goodfellow \& A. G. O'Donnell. Chichester: Wiley.

Collins, M. D. \& Jones, D. (1981). Distribution of isoprenoid quinone structural types in bacteria and their taxonomic implication. Microbiol Rev 45, 316-354.

Denner, E. B. M., Kämpfer, P., Busse, H. J. \& Moore, E. R. B. (1999). Reclassification of Pseudomonas echinoides Heumann 1962, 343 ${ }^{\mathrm{AL}}$, in the genus Sphingomonas as Sphingomonas echinoides comb. nov. Int J Syst Bacteriol 49, 1103-1109.

Ederer, M. M., Crawford, R. L., Herwig, R. P. \& Orser, C. S. (1997). PCP degradation is mediated by closely related strains of the genus Sphingomonas. Mol Ecol 6, 39-49.

Felsenstein, J. (1993). PHYLIP (phylogeny inference package), version 3.5c. Department of Genome Sciences, University of Washington, Seattle, USA.

Jenkins, C. L., Andrewes, A. G., McQuade, T. J. \& Starr, M. P. (1979). The pigment of Pseudomonas paucimobilis is a carotenoid (nostoxanthin), rather than a brominated aryl-polyene (xanthomonadin). Curr Microbiol 3, 1-4.

Kametani, K. \& Matsumura, T. (1983). Determination of ${ }^{238} \mathrm{U},{ }^{234} \mathrm{U}$, ${ }^{226} \mathrm{Ra}$ and ${ }^{228} \mathrm{Ra}$ in spring waters of Sanin district. Radioisotopes 32, 18-21 (in Japanese).

Kämpfer, P., Denner, E. B. M., Meyer, S., Moore, E. R. B. \& Busse, H. J. (1997). Classification of 'Pseudomonas azotocolligans' Anderson 1955, 132, in the genus Sphingomonas as Sphingomonas trueperi sp. nov. Int J Syst Bacteriol 47, 577-583.

Kawahara, K., Seydel, U., Matsuura, M., Danbara, H., Rietschel, E. T. \& Zahringer, U. (1991). Chemical structure of glycosphingolipids isolated from Sphingomonas paucimobilis. FEBS Lett 292, 107-110.

Kosako, Y., Yabuuchi, E., Naka, T., Fujiwara, N. \& Kobayashi, K. (2000). Proposal of Sphingomonadaceae fam. nov., consisting of Sphingomonas Yabuuchi et al. 1990, Erythrobacter Shiba and Shimidu 1982, Erythromicrobium Yurkov et al. 1994, Porphyrobacter Fuerst et al. 1993, Zymomonas Kluyver and van Niel 1936, and Sandaracinobacter Yurkov et al. 1997, with the type genus Sphingomonas Yabuuchi et al. 1990. Microbiol Immunol 44, 563-575.

Lee, J. S., Shin, Y. K., Yoon, J. H., Takeuchi, M., Pyun, Y. R. \& Park, Y. H. (2001). Sphingomonas aquatilis sp. nov., Sphingomonas koreensis sp. nov., and Sphingomonas taejonensis sp. nov., yellow-pigmented bacteria isolated from natural mineral water. Int J Syst Evol Microbiol 51, 1491-1498.

Mesbah, M. \& Whitman, W. B. (1989). Measurement of deoxyguanosine/thymidine ratios in complex mixtures by high-performance 
liquid chromatography for determination of the mole percentage guanine + cytosine of DNA. J Chromatogr 479, 297-306.

Nelis, H. J. \& De Leenheer, A. P. (1989). Profiling and quantitation of bacterial carotenoids by liquid chromatography and photodiode array detection. Appl Environ Microbiol 55, 3065-3071.

Norris, J. R., Ribbons, D. W. \& Varma, A. K. (editors) (1985). Methods in Microbiology, vol. 18. London: Academic Press.

Perrière, G. \& Gouy, M. (1996). WWW-query: an on-line retrieval system for biological sequence banks. Biochimie 78, 364-369.

Rowe, N. J., Tunstall, J., Galbraith, L. \& Wilkinson, S. G. (2000). Lipid composition and taxonomy of [Pseudomonas] echinoides: transfer to the genus Sphingomonas. Microbiology 146, 3007-3012.

Saitou, N. \& Nei, M. (1987). The neighbor-joining method: a new method for reconstructing phylogenetic trees. Mol Biol Evol 4, 406-425.

Silva, C., Cabral, J. M. \& van Keulen, F. (2004). Isolation of a betacarotene over-producing soil bacterium, Sphingomonas sp. Biotechnol Lett 26, 257-262.

Smibert, R. M. \& Krieg, N. R. (1994). Phenotypic characterization. In Methods for General and Molecular Bacteriology, pp. 607-654. Edited by P. Gerhardt, R. G. E. Murray, W. A. Wood \& N. R. Krieg. Washington, DC: American Society for Microbiology.

Takeuchi, M. \& Hiraishi, A. (2001). Taxonomic significance of 2hydroxy fatty acid profiles of the species in the genus Sphingomonas and related taxa. IFO Res Commun 20, 72-82.

Takeuchi, M., Hamana, K. \& Hiraishi, A. (2001). Proposal of the genus Sphingomonas sensu stricto and three new genera, Sphingobium, Novosphingobium and Sphingopyxis, on the basis of phylogenetic and chemotaxonomic analyses. Int J Syst Evol Microbiol 51, 1405-1417.

Thompson, J. D., Higgins, D. G. \& Gibson, T. J. (1994). CLUSTAL_W: improving the sensitivity of progressive multiple sequence alignment through sequence weighting, position-specific gap penalties and weight matrix choice. Nucleic Acids Res 22, 4673-4680.

Tindall, B. J. (1990). Lipid composition of Halobacterium lacusprofundi. FEMS Microbiol Lett 66, 199-202.
White, D. C., Sutton, S. D. \& Ringelberg, D. B. (1996). The genus Sphingomonas: physiology and ecology. Curr Opin Biotechnol 7, 301-306.

Yabuuchi, E. \& Kosako, Y. (2005). Family Sphingomonadaceae Kosako, Yabuuchi, Naka, Fijiwara and Kobayashi 2000b, $1953^{\mathrm{VP}}$. In Bergey's Manual of Systematic Bacteriology, 2nd edn, vol. 2, part C, pp. 230-233. Edited by D. J. Brenner, N. R. Kreig, J. T. Staley \& G. M. Garrity. New York: Springer.

Yabuuchi, E., Yano, I., Oyaizu, H., Hashimoto, Y., Ezaki, T. \& Yamamoto, H. (1990). Proposals of Sphingomonas paucimobilis gen. nov. and comb. nov., Sphingomonas parapaucimobilis sp. nov., Sphingomonas yanoikuyae sp. nov., Sphingomonas adhaesiva sp. nov., Sphingomonas capsulata comb. nov., and two genospecies of the genus Sphingomonas. Microbiol Immunol 34, 99-119.

Yabuuchi, E., Kosako, Y., Fujiwara, N., Naka, T., Matsunaga, I., Ogura, H. \& Kobayashi, K. (2002). Emendation of the genus Sphingomonas Yabuuchi et al. 1990 and junior objective synonymy of the species of three genera, Sphingobium, Novosphingobium and Sphingopyxis, in conjunction with Blastomonas ursincola. Int J Syst Evol Microbiol 52, 1485-1496.

Yang, D. C., Im, W. T., Kim, M. K., Ohta, H. \& Lee, S. T. (2006). Sphingomonas soli sp. nov., a $\beta$-glucosidase-producing bacterium in the family Sphingomonadaceae in the $\alpha-4$ subgroup of the Proteobacteria. Int J Syst Evol Microbiol 56, 703-707.

Yoon, J. H., Lee, M. H., Kang, S. J., Lee, S. Y. \& Oh, T. K. (2006). Sphingomonas dokdonensis sp. nov., isolated from soil. Int J Syst Evol Microbiol 56, 2165-2169.

Zablotowicz, R. M., Leung, K. T., Alber, T., Cassidy, M. B., Trevors, J. T., Lee, H., Veldhuis, L. \& Hall, J. C. (1999). Degradation of 2,4dinitrophenol and selected nitroaromatic compounds by Sphingomonas sp. UG30. Can J Microbiol 45, 840-848.

Zipper, C., Nickel, K., Angst, W. \& Kohler, H. P. (1996). Complete microbial degradation of both enantiomers of the chiral herbicide mecoprop [(RS)-2-(4-chloro-2-methylphenoxy)propionic acid] in an enantioselective manner by Sphingomonas herbicidovorans sp. nov. Appl Environ Microbiol 62, 4318-4322. 